\title{
The Construction of Innovation Group and the Sustainable Development of Innovation Ability for Engineering Students
}

\author{
Yang Renjie (Corresponding Author) \\ College of Engineering and Technology \\ Tianjin Agricultural University \\ Tianjin, China \\ rjyang1978@163.com \\ Yang Yanrong \\ College of Engineering and Technology \\ Tianjin Agricultural University \\ Tianjin, China \\ 1605471320@qq.com
}

\author{
Dong Guimei \\ College of Engineering and Technology \\ Tianjin Agricultural University \\ Tianjin, China \\ 32568403@qq.com \\ Du Yanhong \\ College of Engineering and Technology \\ Tianjin Agricultural University \\ Tianjin, China \\ 19776289@qq.com
}

\begin{abstract}
The sustainable development of economy and society depends not only on the quantity and structure of the talents, but also on the creative spirit and innovation ability of the talents. In this paper, a high-level innovative group of teachers and students was established based on the understanding of the current situation of the construction of teachers and students' innovation team in universities at home and abroad. Firstly, A high level teachers' innovation group was built from the aspects of scientific research environment, incentive mechanism and team cooperation. Taking the undergraduates of the college of engineering and technology as the research object in Tianjin Agricultural University, a high level students' innovation group was built from the aspects of the selection model, training model, and management model. The problems arising in the process were summarized and the schemes were adjusted to form a sustainable development of teachers and students' innovation group. The proposed method provides a reference for other colleges and universities to establish teachers and students' innovation group.
\end{abstract}

Keywords-Higher level; Teachers' innovation group; Students' innovation group; sustainable development; Innovation ability training; Engineering students

\section{INTRODUCTION}

College students are the main force of the modernization of the twenty-first Century, and the society needs innovative talents with high quality. With the development of the society, the requirements for the quality and ability of talents have been gradually improved. Therefore, in the process of carrying out quality education, we should focus on the cultivation of students' innovative spirit and practical ability. In 2014, the goal of implementing the innovation driven development strategy was put forward at the seventh meeting of the central

1. Education Reform and Innovation Development Funds of Tianjin Agricultural University (20170202).

2. Innovation and entrepreneurship training reform model projects of Tianjin Agricultural University (20170812). financial leadership group. The conference emphasizes that innovation is always an important force for the development of a nation. As an engineering department of agricultural university, most undergraduates directly go to work after graduation. Their positions require graduates to have some innovative and creative abilities and spirit of solidarity and cooperation. It is an important subject that how to train them into high quality and innovative talents.

Higher education should pay attention to the cultivation of College Students' creative ability, practical ability and entrepreneurial spirit. The innovation ability has become the primary ability of college students. Therefore, so many teachers have been devoted to the discussion and Research on how to effectively cultivate students' innovative ability. As early as 60 years in the last century, The Massachusetts Institute of Technology in the United States encourages the undergraduates to participate in the research and innovation research projects of teachers to improve their innovation ability. In 80s, University of California at Los Angeles also encouraged undergraduate students to participate in the research of teachers, and built the two centers of undergraduate research [1]. In 1997, in order to cultivate students' innovative ability, University of California at Berkeley established the undergraduate research office, and made remarkable achievements. At home, a lot of teachers have done a lot of research on the construction of innovative team. Jiang Yongrong et al. established the innovative team model of the college students combined the teacher's scientific research project with the students' ability under the guidance of the tutor The research results showed that the model could effectively improve the students' innovation ability [2]. Hu Huojin pointed 
out that the construction of teachers' creative team played a vital role in the cultivation of College Students' innovative quality [3]. Zhang Xiaoping studied the factors that affect the innovation ability of college students, and pointed out that the quality of teachers' innovation played an important role in the process of Cultivating College Students' innovative ability [4]. Lu Jiqing et al. built a platform for the cultivation of scientific and technological innovation for college students based on the concept of CDIO, and achieved good results [5].

From the above research situation at home and abroad, many colleges and universities have made bold and beneficial attempts to cultivate students' innovative ability, and provide some successful experiences for the cultivation of college students' innovative ability. In this paper, from the current situation of the cultivation of students' innovation in our college, and combined with the characteristics of our college and professional students, a model and method for the sustainable development of students' innovation team was built learn from the successful experience of domestic and foreign universities. The proposed method can cultivate the innovative ability of the college students of agricultural engineering, and provide reference for the construction of other professional innovative teams.

\section{BUILDING A High LEVEl OF TEACHERING INNOVATION TEAM}

On the basis of national and provincial level projects and food safety testing platform, a high level of teachers and students' innovation groups were built (Fig.1). The training of innovative talents needs innovative teachers, and the innovation quality of the teachers directly determines the cultivation of College Students' innovative quality [6]. A high level of teachers' innovation group was built from the aspects of scientific research environment, incentive mechanism and team cooperation (Fig.2).

\section{A. Construction of research environment}

The construction of research environment is one of the key factors for the effective operation of the innovative team and the training of the team's scientific research work. Schools should create a harmonious scientific research environment suitable for the development of innovative teachers' group.

(1) The school should improve the personnel training mechanism, encourage young team teachers to take a doctorate in the job, participate in academic exchanges for expanding the field of research. At the same time, the experienced teachers were invited to organize lectures on scientific research projects for improving young teachers' teaching level, scientific research ability, and their academic level.

(2) The school should strengthen the construction of food testing platform. The key laboratories and engineering research centers should also allocate special funds for young teachers in the innovation center to support them in scientific research.
(3) The experienced teachers help young teachers to accelerate the growth of young teachers, and enhance the strength of the teaching and scientific research.

(4) According to the requirements of the agricultural product safety detection platform and team construction, highlevel talents should be introduced, especially the leader of the subject.

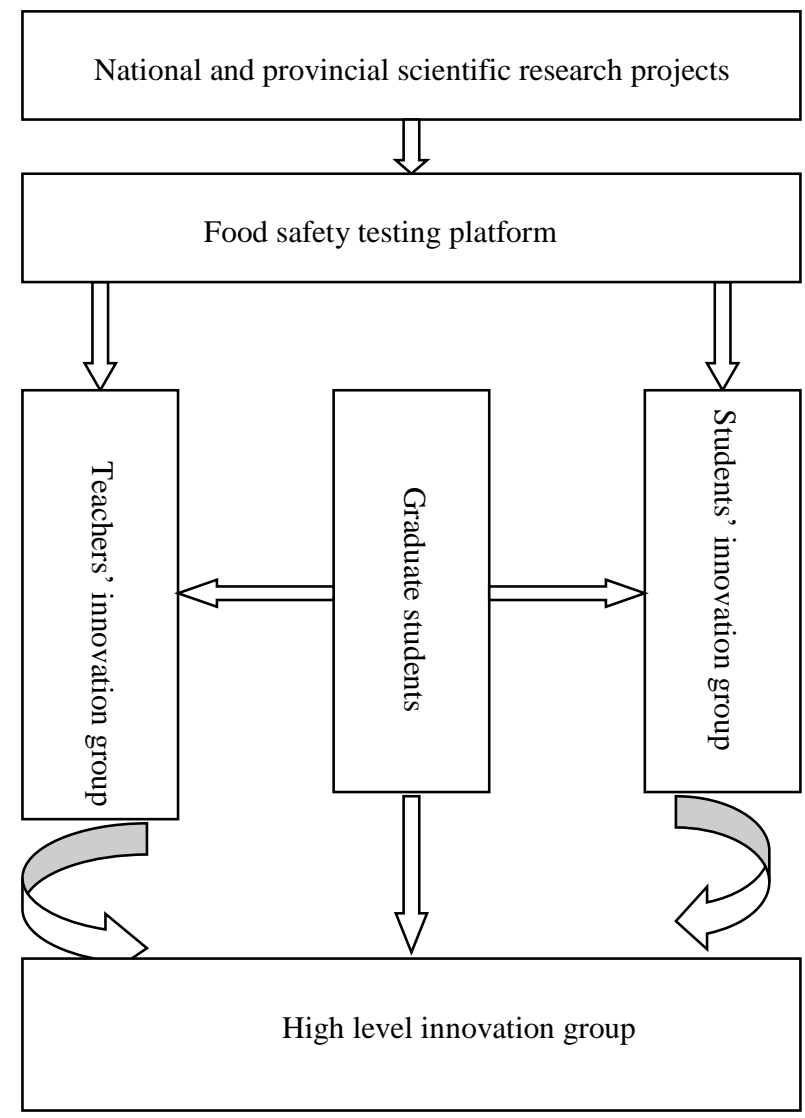

Fig. 1 The construction scheme of high level innovation group

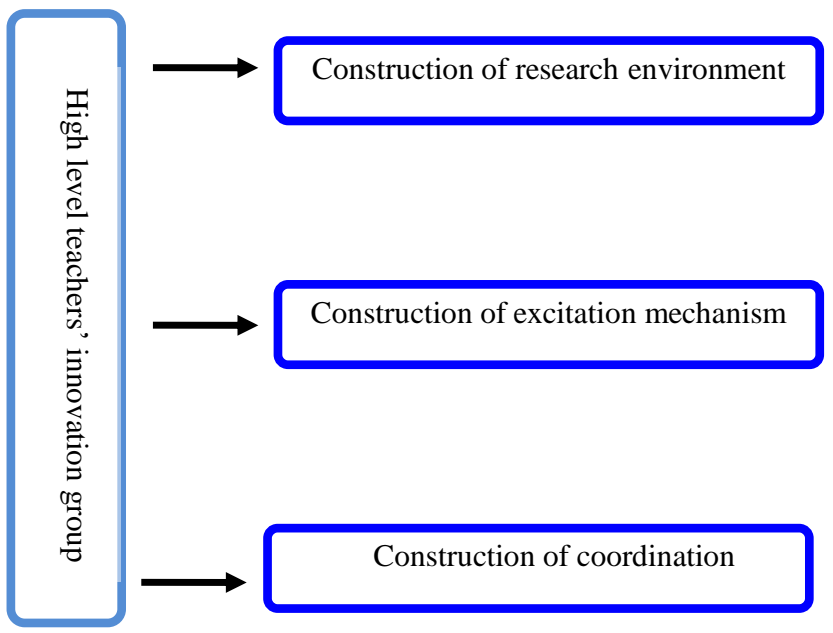

Fig. 2 The construction of high level teachers' innovation group 


\section{B. Construction of excitation mechanism}

At present, the instructors are basically compulsory labor in the scientific and technological innovation activities of college students. Therefore, and some teachers are not willing to guide the students' innovative activities. It has become the key problem of scientific research management team that how to establish an effective restraint and incentive mechanism, fully mobilize the enthusiasm of teachers, to carry on effective encouragement to create a team of teachers, to fully stimulate their ability to create the environment, to establish the effective incentive mechanism of scientific research group

(1) A reasonable teacher assessment and research award system should be built, so that young teachers can mobilize their research from passive to active research and mobilize their research initiative. The management system of the school should be enriched and improved combined material with spiritual incentives.

(2) Young teachers with scientific research ability should reduce the workload of teaching and make them energetic to carry out scientific research work.

(3) The competitive mechanism of the fittest and the income distribution mechanism were introduced in the process of scientific research work.

It is worth noting that the establishment of incentive mechanism should be according to the general requirements. Because different researchers have different requirements, the implementation of incentive process must be open, transparent, and fair.

\section{Construction of coordination}

Scientific research depends on the spirit of group cooperation. The group cooperation spirit has become the basic quality that the researchers should have.

(1) According to the research direction of the teachers in the team, a common construction goal is set up. In order to achieve this goal, team members should mutual help and form a research gradient. At the same time, each member can maximize the potential.

(2) The academic exchanges should be strengthened among team members so as to achieve a good development of innovative teachers' group.

\section{BUILDING A High LEVEL OF STUDENTS' INNOVATION TEAM}

It is an important goal of university education to improve the creative ability of undergraduate students [7]. Taking the undergraduates of the college of engineering and technology as the research object in Tianjin Agricultural University, a highlevel students' innovation group was built from the aspects of the selection model, training model, and management model (Fig.3).

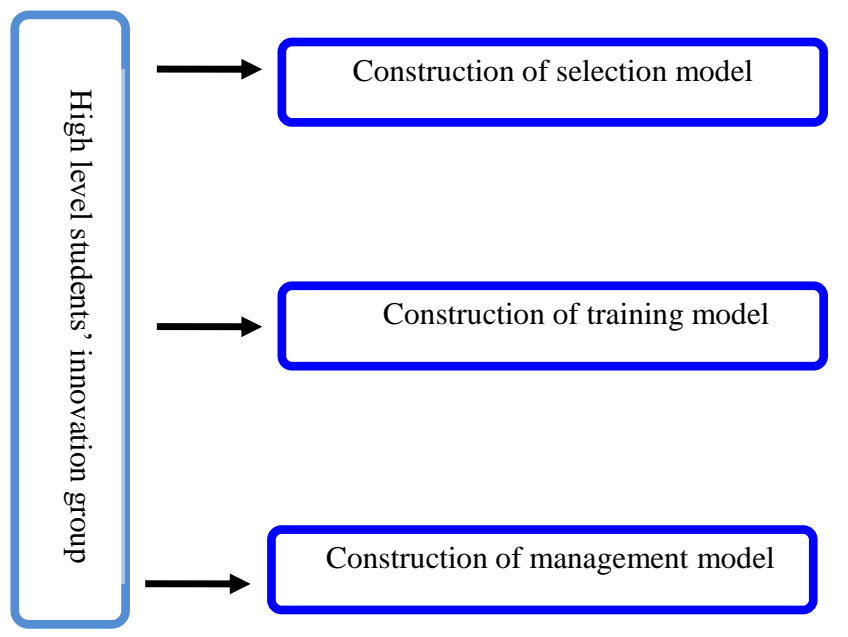

Fig. 3 The construction of high level students' innovation group

\section{A. Construction of selection model}

Innovative undergraduate students need to have comprehensive and excellent comprehensive quality. Therefore, it is very important to select good students to enhance the creative power of undergraduate students. The students in the innovation group should have an open mind and a keen observation, which can be analyzed and solved on the basis of the existing knowledge.

(1) For undergraduates of the college of engineering and technology, the innovative teachers introduce the related project,the professional knowledge and basic skills in the form of academic reports, The enthusiasm of students' declaration has been mobilized. Students volunteered to sign up for innovative activities. The innovative teachers interview the initial selected students. The interviews include the theoretical and experimental parts to determine the members of students' innovative group.

(2) Because different teachers have different research directions and subjects, they need different knowledge structure talents. Therefore, the innovation team teachers choose appropriate talents from innovative team members to cultivate according to the needs of the projects. 


\section{B. Construction of training model}

(1) Group members should be encouraged to apply for college students' innovation projects, so as to enhance undergraduates' innovative consciousness and innovative ability training, and give full play to their innovative advantages and innovative potentials. Teachers should encourage undergraduate students to make bold innovations, especially original research, and cultivate high-level talents.

(2) Colleges should strengthen the support for scientific and technological innovation of college students, and provide basic material support and fund support. Not only improve the hardware facilities such as opening laboratories, libraries, classrooms, but also select experienced and qualified teachers to guide students. This can not only guarantee the quality of students' scientific research, but also improve the research level of the teacher.

(3) The teachers carry out the relevant academic reports for the students and carry out the academic discussion.

(4) The three level training model for teachers, graduate students and undergraduate students was established to cultivate students' innovative ability.

\section{Construction of management model}

Good group management is an important guarantee for training innovative team's scientific research ability. Therefore, the management of students' innovation group must be scientific, institutionalized and standardized, so as to provide strong guarantee for enhancing innovative undergraduate's scientific research ability.

(1) Selection is the first step to enhance innovative ability of innovative undergraduates. Therefore, the selection system of the members of the innovative group needs continuously reform and improve.

(2) The competition mechanism and incentive mechanism can greatly promote the formation of students' creativity and innovation spirit. Teachers should strengthen communication with student and encourage students to engage in research topics or research directions of interest. At the same time, teachers should give guidance and help to students' research direction and employment choice, and make goals and emotional incentives.

(3) The school should constantly improve the assessment system. The students first report their most innovative research results, and teachers carry out a comprehensive assessment. In this way, students' scientific research ability and innovation ability can be focused on to determine whether they still have potential for training, and whether they can make innovative achievements.

\section{CONCLUSION}

In this paper, the undergraduates of the college of engineering and technology were taken as research object in Tianjin Agricultural University. A model and method for the sustainable development of teachers and students' innovation group was built combining theory with practice. The established model and method can effectively cultivate students' innovative spirit, innovative ability and teamwork spirit, and improve the students' ability to analyze and solve problems.

\section{ACKNOWLEDGEMENT}

This work was financially supported by the Education Reform and Innovation Development Funds of Tianjin Agricultural University (20170202), and innovation and entrepreneurship training reform model projects of Tianjin Agricultural University (20170812).

\section{REFERENCES}

[1] Cave. The use of performance indications in higher education: a critical analysis of developing practice. Jessica Kings leg Publishers Ltd, 1987.

[2] Jiang Yongrong, Li Tianyu, Jiang Dongyun et al. Exploration and practice of establishing mode for scientific researching innovation group of undergraduate $[\mathrm{J}]$. Journal of Guilin University of Electronic Technology, 2008, 28(4):376-378.(In Chinese)

[3] Hu Huojin. The construction of teachers' team and the cultivation of college students' innovative quality [J]. Fujian Forum, 2011, 12:197-198. (In Chinese)

[4] Zhang Xiaoping. Study on the teachers' factors of affecting the cultivation of college students' innovation ability [J]. China Adult Education, 2016, 7 : 84-88.(In Chinese)

[5] Lu Jiqing, Chen Ziwei. Construction on Scientific and Technological Innovation Platform for the College Students Based on CDIO [J]. Education Teaching Forum, 2017, 1: 167-168. (In Chinese)

[6] He Nong. Study on the construction of teachers' creative team in Higher Vocational Colleges [J]. Heilongjiang Researches on Higher Education, 2008, 7: 118-120. (In Chinese)

[7] Zhao $\mathrm{Yu}$. Exploration on establishment model of student team for the application and innovation of the new colleges [J]. Heilongjiang Agricultural Sciences, 2012, 6: 137-138. (In Chinese) 